\title{
Teatro e sala de aula: diálogos possíveis. Um relato de experiência
}

\author{
Theater and classroom: possible dialogues. An experience report
}

Selmo Alves ${ }^{1}$

\begin{abstract}
RESUMO
O surgimento da arte de representar confunde-se com a própria história humana, já que o homem primitivo usava os rituais para agradecer ou celebrar os acontecimentos do cotidiano ou até mesmo promovia encenações sagradas para controlar fenômenos da natureza. Os egípcios transformavam os pequenos rituais em grandes rituais baseados em mitos. Mais tarde, na Grécia, surge o "ditirambo", uma espécie de procissão informal que servia para homenagear o deus Dioniso. Na escola, o teatro começa já na infância através do "faz de conta" e da imitação da realidade, ajudando a desenvolver a criatividade e a comunicação, favorecendo a aprendizagem. Trata esse artigo de um relato de experiência pedagógica que buscou na dramatização inspiração e elementos que pudessem subsidiar a ação educativa na promoção de aprendizagens significativas. Para tanto, lança como foco central o uso de estratégias que valorizem o entretenimento enquanto pretexto, por meio do qual possam ser trazidas para o processo formativo em si dimensões pedagógicas alicerçadas no socioafetivo, permitindo aos sujeitos da aprendizagem a imersão num mundo recriado a partir das percepções e vivências pessoais, cujo pano de fundo é exatamente a realidade concreta.
\end{abstract}

Palavras-chave: Arte dramática; Escola; Ensino; Aprendizagem; Experiência.

\begin{abstract}
The emergence of the art of acting is confused with human history itself, since the early man has used rituals to thank or to celebrate everyday events or even promoted sacred enactments to control nature's phenomena. The Egyptians turned small rituals into great myth-based rituals. Later, in Greece, comes the "dithyramb", a kind of informal procession that served to honor the god Dionysus. At school, theater begins in childhood through "make-believe" and imitation of reality, helping to develop creativity and communication, favoring learning. This article is an account of pedagogical experience that sought in the role play inspiration and elements that could support the educational action in the promotion of meaningful learning. To this end, it launches as its central focus the use of strategies that value entertainment as a pretext, through which they can be brought into the educational process pedagogical dimensions based on socio-affective, allowing the subjects of learning to immerse themselves in a world recreated from the personal perceptions and experiences, whose background is exactly the concrete reality.
\end{abstract}

Keywords: Dramatic Art; School; Education; Learning.

${ }^{1}$ Doutor em Educação pela Universidad Tecnológica Intercontinental (UTIC), mestre em Estudo de Linguagens pela Universidade do Estado da Bahia (UNEB), professor na educação básica e universitária e pedagogo na Universidade Federal da Bahia (UFBA). E-mail: profselmoalves@yahoo.com.br / selmo.alves@ufba.br 


\section{Introdução}

O mundo é um teatro e cada um de nós, individualmente ou em grupo, teatraliza ou é ator consoante as circunstâncias em que nos encontremos, marcados por rituais posições distintivas relativamente a outros indivíduos ou grupos. (GOFFMAN, Erving, 1967)

Há controvérsias sobre a real origem da arte de representar. Não é possível datar exatamente quando nasceu o teatro, mas é possível dizer que surgiu com a necessidade do homem de contar histórias e acontecimentos. Segundo Lehmann (2007), cerimônia, rito e festividade sempre existiram nos grupos humanos e marcaram todas as manifestações cênicas desde as culturas mais primitivas, sendo o mito uma de suas razões fundamentais. Conforme Chauí (2004), a palavra mito vem do grego mythos e deriva de dois verbos: mytheyo (contar, narrar, falar alguma coisa para outros) e mytheo (conversar, contar, anunciar, nomear, designar). É uma narrativa sobre a origem de algumas coisas (origem dos astros, da Terra, dos homens, dos elementos naturais, da saúde, da doença, da morte etc.).

Alguns consideram que tal fenômeno sempre acompanhou a vida do homem no seu cotidiano, nos rituais de celebração e de agradecimento (no caso de uma boa colheita, por exemplo), de tentativa de domínio dos efeitos da natureza, ou até mesmo nos eventos de sacralização. Há quem credite o surgimento do teatro ao povo egípcio, através dos rituais de representação dos mitos. Há, porém, quem credite a criação do teatro à Grécia antiga, por volta do séc. IV a.C., nas encenações religiosas em homenagem ao deus Dioniso. Controvérsias à parte, fato é que a arte de representar faz parte da vida social do homem nos vários domínios em que ele se encontre, seja para mostrar à virtude seus próprios traços, seja para mostrar à infâmia sua própria imagem, e dar à própria época sua forma e aparência (cf. HAMLET, Ato III, cena II).

Vale ressaltar que, na época das cavernas, a linguagem não era codificada verbalmente. Assim, quando alguém precisava contar algo para um amigo, era necessário usar o corpo como forma de expressão. Isso mostra que o uso do corpo, há muito tempo, já era instrumento de representação e precede o uso da voz nas representações dramáticas.

No âmbito da escola, não há registros precisos sobre a partir de quando o teatro surgiu, talvez quando as histórias infantis passaram a ser contadas, mas o que não se pode negar é que o teatro é usado como uma importante e rica estratégia para desenvolver habilidades e competências criativas que possam ajudar na aprendizagem dos alunos, além de favorecer a expressão corporal e verbal e trabalhar a inibição e os sentimentos. Por causa disso, o faz de conta e as imitações sempre fizeram parte das atividades escolares. Desse modo, segundo Nazareth (apud MIRANDA, 2009, p.172): 
A arte é libertária e o teatro é, sem dúvida, das artes, a expressão por excelência. A possibilidade de "reviver" sentimentos e situações sem barreiras de tempo e espaço, de presenciar fatos de verdade ocorridos ou apenas existentes no imaginário do autor, possibilita resgate do indivíduo e da sociedade.

O texto indica que o teatro é o maior recurso de libertação do indivíduo na vida social através do resgate do mundo vivido ou imaginado. De uma forma ou de outra, uma coisa é certa: o teatro é, seguramente, uma linguagem por meio da qual o indivíduo revive as experiências e dá vazão a situações e sentimentos do cotidiano.

Os clássicos da literatura ou os temas e culturas locais costumam ser explorados nas salas de aula. A própria contação de histórias constitui uma estratégia teatral. No caso do Brasil, reconhece-se que a implantação do teatro com perspectiva pedagógica deve-se aos jesuítas para catequizar os índios.

Com o passar do tempo, o teatro vai perdendo sua finalidade primeira, na Grécia, de sacralização ou de celebração, e adota a função de divertimento e prazer. Desse modo, as civilizações, na medida em que vão evoluindo, afastam-se da cultura grega e assumem seu próprio estilo, e as tragédias gregas, que se baseavam em competições entre os romanos e os cristãos, que resultavam em sacrifícios públicos deles, vão assumindo novos formatos e dando lugar à comédia. Nas tragédias gregas, os temas eram ligados às leis, à justiça e ao destino. Nes- se gênero, eram contadas histórias que quase sempre terminavam com a morte do herói.

Os autores de tragédia grega mais famosos foram Ésquilo, Sófocles e Eurípedes. Ao contrário da tragédia, na comédia grega, as histórias visavam ao riso do espectador, eram formas engraçadas de perceber a vida, chamadas de sátiras, transformando o sagrado em profano. Um grande autor de comédia grega foi Aristófanes. Todos esses autores influenciaram muito o teatro que veio depois e suas peças são encenadas até hoje. A seguir, há um mapeamento dos autores de teatro mais importantes e as suas contribuições:

Ésquilo (525 - 456 a.C.) foi um autor reconhecido pelo elogio às conquistas de Atenas e pela homenagem aos deuses justiceiros. Em Os persas, ele discorre sobre os principais acontecimentos ligados às guerras Grecopérsicas e realiza uma crítica à prepotência do rei Xerxes. As peças de Ésquilo foram inovadoras ao promover a utilização de diálogos, máscaras e coros que conferiam maior dramaticidade às suas histórias. Esse escritor também foi responsável pela criação de Oréstia e Os Sete contra Tebas.

Sófocles (496 - 406 a.C.), autor das obras Édipo Rei, Antígona e Electra, privilegiou a luta dos heróis contra o destino e a influência que os deuses possuíam na vida dos homens. Em Édipo Rei, tem-se a história de um protagonista que mata seu pai e se casa com a própria mãe sem ter ciência do que ocorria. Com as peças de Sófocles, as encenações passaram a contar com 
a presença de um terceiro interlocutor no palco. Dessa forma, o número de personagens em uma história aumentava.

O escritor Eurípedes (445 386 a.C.) tinha forte espírito crítico e tratava com pessimismo as situações envolvendo a vida cotidiana e os costumes de seu povo. As personagens que surgem nas obras As Troianas, Medeia, Andrômaca e Hipólito geralmente discutem as paixões e a miséria do homem. Por acreditar que as mulheres eram mais sujeitas a esse tipo de situação, tem-se no legado teatral desse autor uma forte presença da figura feminina.

Nesse sentido, enquanto exercício do espírito humano, o teatro não pode ser definido rigidamente por meio do estudo de um período ou civilização específica. A ideia de se representar o mundo vivido ou alguma situação ficcional está intrinsecamente ligada ao momento em que o homem se viu tentado a transmitir uma determinada experiência ou sensação. Contudo, entre os povos de toda a Antiguidade, não se pode deixar de reconhecer a especial contribuição dos povos gregos ao desenvolvimento desta instigante arte.

\section{$O$ teatro enquanto linguagem $\mathrm{e}$ representação sociocultural}

A linguagem teatral favorece as representações da cultura local, popular ou erudita, resgatando nos humanos as questões mais íntimas, que dizem respeito ao seu cotidiano. $\mathrm{O}$ teatrólogo Augusto Boal aponta como essencial na prática teatral a possibilidade de "todos os seres humanos serem atores". Para ele, "teatro é algo que existe dentro de nós". Boal dimensiona o sentido real do teatro, afirmando que "a linguagem teatral é a linguagem humana por excelência, e a mais essencial".

Por tal prisma, interessa salientar que, através das representações, os sujeitos podem "re-viver" ou reinventar suas vivências e histórias e estabelecer um diálogo com as questões pessoais e sociais locais. O teatro, então, funcionaria como um canal importante de comunicação entre os sujeitos com o seu meio social, quiçá melhorando com este o seu tipo de relação.

O teatro sempre esteve presente em vários momentos, ao longo da história, servindo muitas vezes para representar algumas situações e divertir o público, além de ser utilizado de forma pedagógica, transmitindo determinados valores para seu públicoalvo, ou utilizado como uma forma de melhor assimilação de alguns preceitos. Mas a essência do teatro se reafirma no ser reflexivo e social, de onde advém a importância de ser explorado na escola. Com a inserção do teatro na escola para retratar a realidade dos alunos ou apenas para reinventá-la, de certo modo, valoriza-se e motiva-se o aluno como indivíduo e ser social pertencente a determinado grupo, tendo em vista a coletividade no processo de encenação. Logo, a representação propicia um grau de entretenimento, pertencimento e de pensar entre os sujeitos e o meio em que vivem. 
Ao se utilizar, por exemplo, o trabalho com representações sociais através da construção do texto da peça e da cena em si, contribuir-se-á para uma melhor aprendizagem, pois, ao mesmo tempo em que exige do aluno um maior entendimento, reflexão e aprofundamento do tema, requer a contextualização do trabalho que se está produzindo, montando. Assim sendo, ao se estudar determinada sociedade para elaborar uma peça, os alunos a compreenderão em todos os seus aspectos, identificando e apreendendo traços culturais marcantes. Desse modo, os alunos poderão: “[...] Identificar o modo como em diferentes lugares e momentos uma determinada realidade é construída e dada a ler" (CHARTIER,1990, p.16).

Portanto, importa destacar, nesse aspecto, que o trabalho de representação não se dá no vazio ingênuo dos acontecimentos, mas antes de tudo, impõe uma certa problematização, elaboração e criticidade da produção.

\section{Teatro e escola: breves considerações}

O teatro, quando bem utilizado pelo professor, desenvolve a criatividade, a interdisciplinaridade, a pesquisa, o trabalho em grupo, contribuindo, dessa forma, para otimização das relações sociais, dos aspectos afetivos e cognitivos. Ao trabalhar com peças, o aluno se sentirá como sujeito ativo e integrante de um processo social.

Deve-se ressaltar que os benefícios da linguagem teatral para o desempenho pessoal e profissional dos estudantes são reconhecidos nos $\mathrm{Pa}$ râmetros Curriculares Nacionais PCN Artes, que destacam o seguinte:

Ao participar de atividades teatrais, o indivíduo tem a oportunidade de se desenvolver dentro de um determinado grupo social de maneira responsável, legitimando os seus direitos dentro desse contexto, estabelecendo relações entre o individual e o coletivo, aprendendo a ouvir, a acolher e a ordenar opiniões, respeitando as diferentes manifestações, com a finalidade de organizar a expressão de um grupo. (BRASIL, 1997 , p. 83)

A exploração da linguagem teatral como estratégia pedagógica amplia a capacidade criativa e expressiva do aluno e a atuação didática do professor, sendo este não mais o protagonista do processo, o detentor nem o transmissor de informações, mas um mediador, o que acaba minimizando o suposto distanciamento entre professor e aluno, já que ambos assumem papel colaborativo. Nesse caso, segundo Almeida (2003, p.52): “[...] Atribui-se à mediação o dever ou a possibilidade de eliminar ou minimizar a diferença entre os termos ensino e aprendizagem ou conhecimento sistemático e experiência cotidiana, ou, ainda entre o professor e o aluno".

No caso do Brasil, é nos séculos XV e XVI que o teatro passa a ser utilizado de forma pedagógica, tendo em vista as missões jesuíticas da época, que tinham a finalidade de catequizar os índios e, muitas vezes, eram estes que encenavam passagens bíblicas, como meio de aprendizagem e de 
assimilação dos ideais cristãos, ou seja, uma aculturação desses nativos.

O teatro, visto por uma perspectiva educacional, faz a junção de imaginação e prática, desenvolvendo o potencial dos alunos. Além disso, contribui sobremaneira para a formação de um sujeito crítico, diferentemente do aluno apenas receptor, que acumula informações, característica muito comum no sistema convencional de ensino, em que a memorização tinha papel-chave.

Alguns autores entram em consenso no que diz respeito à relação entre teatro e educação, como Japiassu (2001) e Courtney (2001), sendo o uso do teatro na educação como essencialista e instrumentalista. Nesse caso, conforme Hauer (2005), pode-se entender essa relação da seguinte forma:

Por essencialismo entende-se o uso do teatro na educação preservandose toda sua pureza estética, ou seja, deve-se almejar a qualidade técnica do espetáculo em todos os seus componentes [...]. Já o instrumentalismo no teatro em educação se refere ao teatro como meio para se atingir um fim estranho à atividade teatral, como a aprendizagem de conteúdos extra teatrais, por exemplo, sem haver necessariamente uma preocupação com a qualidade técnica do espetáculo ou com a formação estética do educando envolvido nessa atividade. (HAUER, 2005, p. 24)

Dois tipos de concepção caracterizam o uso do teatro com função pedagógica: o instrumentalismo e o essencialismo. No caso do essencialismo, valoriza-se a qualidade ou pure- za estética do espetáculo. O instrumentalismo, no entanto, ao utilizar a concepção instrumental, acaba por não se preocupar com as "técnicas e materiais" teatrais para alcançar seus objetivos, resultando numa desconsideração da linguagem teatral. O interessante é utilizar ambos os conceitos, aliandose, assim, uma boa encenação ao aprendizado do conteúdo e ao senso crítico dos alunos.

A utilização do teatro enquanto estratégia pedagógica, nesse sentido, tem grande potencial a ser explorado na escola, que, de maneira lúdica, faz com que os alunos cada vez mais se envolvam com a história que está sendo contada, exercitando sua criatividade e a capacidade do desenvolvimento das mais variadas informações, além de estimular o crescimento da linguagem oral e consequentemente corporal.

Portanto, na utilização do teatro com função pedagógica, é interessante salientar que o "[...] o importante não pode ser o produto final, mas o processo" (CARTAXO, 2001, p. 34), ou seja, deve-se dar importância a todo o processo desde a criação do texto, do roteiro, os figurinos, a composição do cenário. Ao se representar determinada sociedade, é necessário aprofundar os estudos sobre ela, compreender hábitos de determinados povos e isso vai desenvolvendo-se ao longo do processo da formação da peça, tendo seu auge na apresentação. Assim sendo, é de extrema importância o conhecimento que os alunos vão adquirindo durante todo o processo, numa posição protagonista. 


\section{Relato de experiência: o teatro e a produção de multilinguagens}

O trabalho foi realizado com discentes do $5 .^{\circ}$ semestre do Curso de Licenciatura em Pedagogia das Faculdades Integradas Ipitanga (FACIIP), situada na cidade de Lauro de Freitas/Bahia, no 2. ${ }^{\circ}$ semestre letivo de 2014.2, no turno da noite, tendo por finalidade a aplicação de novas e diversas metodologias na produção de trabalhos com o tema gerador do semestre, "Pedagogia Sustentável", e os seguintes subtemas: infraestruturas pouco sustentáveis das cidades, lixo doméstico, industrial ou hospitalar, água, esgoto, poluição sonora, visual, ambiental, de rio, mar, praças, parques etc. Assim, a turma foi dividida em três subgrupos, para que cada grupo abordasse de forma diferenciada o tema gerador, com base num projeto elaborado pelo professor da disciplina Produção Textual e Literatura InfantoJuvenil, que culminou com as apresentações dos grupos em dois dias, nos dias 24 e 26/11/2014, na quadra de eventos da faculdade, onde cada grupo apresentaria seu trabalho.

$\mathrm{O}$ primeiro grupo explorou o gênero "contação de história", o segundo grupo explorou o gênero "cordel" e o terceiro grupo explorou o gênero "poema". Todos os grupos, a partir da escolha de um gênero discursivo, tiveram a incumbência de trabalhá-lo de forma dramatizada.

O trabalho resultou de uma proposta transdisciplinar envolvendo as disciplinas Produção Textual e Literatura Infanto-Juvenil, Multicultura- lismo, Avaliação Institucional e da Aprendizagem e Planejamento Educacional. O objetivo da proposta foi desenvolver atividades acadêmicas numa perspectiva transdisciplinar com professores e estudantes do $5 .^{\circ}$ semestre letivo do Curso de Pedagogia, a partir do eixo temático "Pedagogia Sustentável”, tendo como propósito atingir a comunidade acadêmica das FACIIP, principalmente os discentes de todos os cursos, acerca da temática do semestre.

A proposta do trabalho contemplou as seguintes dimensões: Título da Atividade - Multiletramentos Sustentáveis: Invadindo espaços para mudar concepções e práticas; Estratégia - Atividades com jogos dramáticos interativos itinerantes nos vários espaços das FACIIP.

Vale destacar, ainda de acordo com a proposta, que os grupos deveriam explorar/valorizar as ações individuais e, sobretudo, coletivas dos sujeitos, focalizando, preferencialmente, personagens da cultura brasileira/local (de Lauro de Freitas, especialmente), numa perspectiva multicultural, fazendo-se passar por defensores do desenvolvimento sustentável. Ressalta-se a importância da escolha da indumentária (roupas e acessórios e disfarces, como máscaras, por exemplo, das personagens que forem escolhidas etc.), como recurso para caracterizar as referidas personagens, dificultar a identificação dos estudantes e minimizar a timidez, permitindo-lhes uma melhor performance.

Dessa maneira, trabalhar com temas variados, a partir de diferentes fontes, linguagens, suportes, gêneros 
discursivos e tipologias, constitui uma escolha pedagógica que pode contribuir de forma significativa para que os educandos desenvolvam competências e habilidades que lhes permitam apreender as várias questões nas quais os diferentes sujeitos sociais desenvolveram ou desenvolvem suas ações, condição básica para que sejam identificadas as diferentes formas de as histórias serem contadas, elemento este bastante significativo no trabalho do grupo por se tratar de sujeitos no contexto de formação docente.

Portanto, os alunos foram desafiados, no que diz respeito à apresentação dos trabalhos, tendo em vista que seriam apresentados para toda a faculdade num espaço aberto e itinerante. Vale ressaltar que, ao mesmo tempo em que os alunos puderam pesquisar e resgatar aspectos da cultura local, a partir do tema gerador, também puderam perceber como as diferentes metodologias enriquecem o trabalho pedagógico.

Pode-se constatar, com a realização dos trabalhos, que os alunos se sentiram entusiasmados em produzir as representações e cada um pôde colaborar nas diversas fases: elaboração do roteiro, personagens, cenários, figurino. Através das representações, puderam conhecer melhor a cultura local, compreendendo os desafios na superação de impasses existentes em relação à temática da sustentabilidade da cidade.

\section{Considerações finais}

Percebe-se que a introdução da linguagem artística, nesse caso, o tea- tro, contribui significativamente no processo de ensino-aprendizagem em linguagens, já que estas se manifestam de forma intensa, rica e variada, principalmente nos meios letrados contemporâneos.

Além de ser uma forma de gerar o interesse dos alunos no estudo de linguagens, promove envolvimento e vivências nas questões que dizem respeito aos diferentes textos e gêneros discursivos, além, obviamente, de despertar o interesse sobre cenários, cenas, personagens, músicas e vestuários e fazer com que se sintam participantes ativos no processo de aprendizagem. Desse modo, a busca de caminhos diferentes pode tornar o estudo mais agradável e permitir que os alunos se sintam mais envolvidos com as questões trazidas e problematizadas.

Mas deve-se levar em consideração que a utilização do teatro como estratégia pedagógica não é a solução para resolver todos os problemas no processo de ensino-aprendizagem, pois é um recurso que possui aspectos que podem funcionar de forma negativa, caso não haja uma boa preparação do trabalho. Deve-se destacar que o papel do professor como importante mediador do processo necessita ser também levado em conta.

Por fim, com a realização do trabalho, pode-se constatar que o uso das representações, a partir da mistura das concepções instrumentalista e essencialista, como já mencionado nesse artigo, proporciona que os alunos rompam com sua posição passiva $\mathrm{e}$ receptiva de informações e se reconheçam enquanto sujeitos ativos e críticos 
de todo o processo. Por se tratar de uma metodologia que requer a mobilização dos sujeitos, os alunos acabam criando ou descobrindo, com o proces- so de elaboração das apresentações, condições mais favoráveis para que estas ocorram da melhor maneira possível. 


\section{Referências}

ALMEIDA, José Luiz Vieira de. A mediação como fundamento da didática. In: Tópicos de educação. São José do Rio Preto, SP: Rio-pretense, 2003, p.61-76.

BOAL, A. Jogos para Atores e não Atores. Rio de Janeiro: Civilização Brasileira, 2000 .

BRASIL. Secretaria de Educação Fundamental. Parâmetros Curriculares Nacionais - Arte. Brasília: MEC/SEF, 1997.

CARTAXO, C. O ensino das artes cênicas na escola fundamental e média. João Pessoa: Editora da UFPB, 2001.

CHARTIER, R. A História Cultural: entre práticas e representações. Lisboa/Rio de Janeiro: DIFEL/B. Brasil S/A, 1990, p.16-17.

CHAUI, Marilena. Filosofia. São Paulo: Ática, 2004.

COURTNEY, R. Jogo, Teatro \& Pensamento: As Bases Intelectuais do Teatro na Educação. 2. ed. São Paulo: Editora Perspectiva, 2001.

HAUER, Rafael Mauricio. Linguagem teatral e aquisição de conteúdos escolares: uma perspectiva cultural e histórica. Curitiba: Martins Fontes, 2005.

JAPIASSU, R. O. V. Metodologia do ensino de teatro. Campinas: Papirus, 2001.

LEHMANN, Hans-Thies.Teatro Pós-Dramático. São Paulo: Cosac Nayf, 2007.

MIRANDA, Juliana Lourenço et al. Teatro e a Escola: funções, importâncias e práticas. Revista CEPPG, n. 20 - 1/2009 - ISSN: 1517-8471 - p.172-181.

SHAKESPEARE, W. Hamlet. Tradução de Millôr Fernandes. São Paulo: Editora Peixoto Neto, 2004.

$O(s)$ autor(es) se responsabiliza(m) pelo conteúdo e opiniões expressos no presente artigo, além disso declara(m) que a pesquisa é original.

Recebido em 12/03/2020

Aprovado em 26/06/2020 